\title{
Developmental Pathways and Specification of Intrapulmonary Stem Cells
}

\author{
ZEA BOROK, CHANGGONG LI, JANICE LIEBLER, NEEMA AGHAMOHAMMADI, VEDANG A. LONDHE, AND \\ PARVIZ MINOO
}

\begin{abstract}
Department of Medicine [Z.B., J.L., N.A.], Will Rogers Institute Pulmonary Research Center, Department of Pediatrics [C.L., P.M.], Keck School of Medicine, University of Southern California, Los Angeles, CA 90033; Department of Pediatrics [V.A.L.], David Geffen School of Medicine at UCLA, Los Angeles, CA 90095
\end{abstract}

\begin{abstract}
Tissues have the capacity to maintain a homeostatic balance between wear-and-tear and regeneration. Repair of nonlethal injury also activates cell proliferation to repopulate the injured sites with appropriate cell types and to restore function. Although controversial, the source of the material appears to be at least partly from pools of unique, multipotent stem cells that reside in specialized locations referred to as "niches." Molecular interactions between the niche and the intracellular factors within stem cells are crucial in maintaining stem cell functions, particularly the balance between self-renewal and differentiation. Many of the mediators of the stem cell-niche interactions are similar or identical to those that control developmental pathways during organogenesis. In this review, we present a systematic discussion and evaluation of the relevant literature with a focused emphasis on three primary signaling pathways, WNT, SHH and BMP with potentially overlapping roles during both development and stem cell maintenance. (Pediatr Res 59: 84R-93R, 2006)
\end{abstract}

$\mathrm{C}$ lassical observations by early embryologists on tissue regeneration in segmented worms such as polychaetes and oligochaetes suggested that fully differentiated adult tissues may harbor unique cells that retain the capacity for regeneration. Some tissues, such as the intestine, hair follicle and liver, have been more amenable to identification and characterization of these so-called resident stem cells due primarily to faster turnover rate. In other organs, including the lung, these cells have been more elusive and their contribution to regeneration in the adult more difficult to decipher. What appears certain, however, is that adult tissues have the capacity to maintain a homeostatic balance between wear-and-tear and regeneration. Furthermore, the response of tissues to nonlethal injury in most cases activates repair mechanisms that involve cell proliferation and repopulation of injured areas with appropriate cell types to restore function. Although controversial, the source of the repairing tissue is at least

Received December 13, 2005; accepted December 15, 2005.

Correspondence: Parviz Minoo, Ph.D., University of Southern California, Keck School of Medicine, Department of Pediatrics, 1801 E. Marengo Street, Rm 1G1 or 1G38, Los Angeles, CA 90033; e-mail: minoo@hsc.usc.edu.

The research in the authors' laboratories is funded by NHLBI, NIH and the Hastings Foundation.

DOI: $10.1203 / 01 . p d r .0000203563 .37626 .77$ partly from pools of unique cells present in various tissues whose identity can be determined by two simple criteria: 1) the capacity for self-renewal; and 2) the ability to differentiate into more than one cell type. These two criteria are commonly used to define "stem cells" in general, including those embedded within the bone marrow (BM). BM-derived stem cells recently have been a topic of special interest, particularly as far as their therapeutic potential is concerned. This review's focus will be solely on lung-embedded stem cells. There are other highly informative recent reviews on related topics that complement the specific areas covered in this review $(1,2)$. In addition, the hotly debated topic of BM stem cells is excellently treated by Thebaud et al. in the same issue of the journal.

\section{DEVELOPMENTAL POTENTIAL AND STEM CELLS}

Stem cells are thought to be developmentally primitive and rare in number. The ability of cells to differentiate along various lines is referred to as developmental potential. Hence the zygote is developmentally totipotent since it can give rise to all cells within the embryo and the placenta (Fig. 1). Pluripotent stem cells have a more restricted developmental potential and can form only the cells found in the embryo. Further restrictions during embryonic development give rise to multipotent stem cells that form all three germ layers: endoderm, mesoderm and ectoderm. Tissue-committed stem cells, sometimes referred to as "progenitor" cells are also multipotent, but are more restricted in their differentiation potential, being capable of giving rise only to a limited subset of the cell lineages found within a given organ. Recent demonstrations of adult stem cell plasticity however, have challenged this concept (3). Thus, simply based on their developmental potential, stem cells can be divided into two major types: embryonic stem cells are derived from the inner

Abbreviations: APC, adenomatous polyposis coli; AT1 (2), alveolar epithelial type 1 (2) cells; BADJ, bronchoalveolar duct junction; BASC, bronchoalveolar stem cell; BM, bone marrow; BMP, bone morphogenetic protein; CCSP, clara cell specific protein; GSC, germline stem cell; K5 (14), keratin 5 (14) promotor; LRC, label-retaining cell; NEB, neuroepithelial body; PNEC, pulmonary neuroendocrine cell; PTC, patched; SHH, sonic hedgehog; SP, side population; SP-C, surfactant protein C; SVZ, subventricular zone; TA, transit amplifying; WNT, wingless; vCE, variant CCSP-expressing 


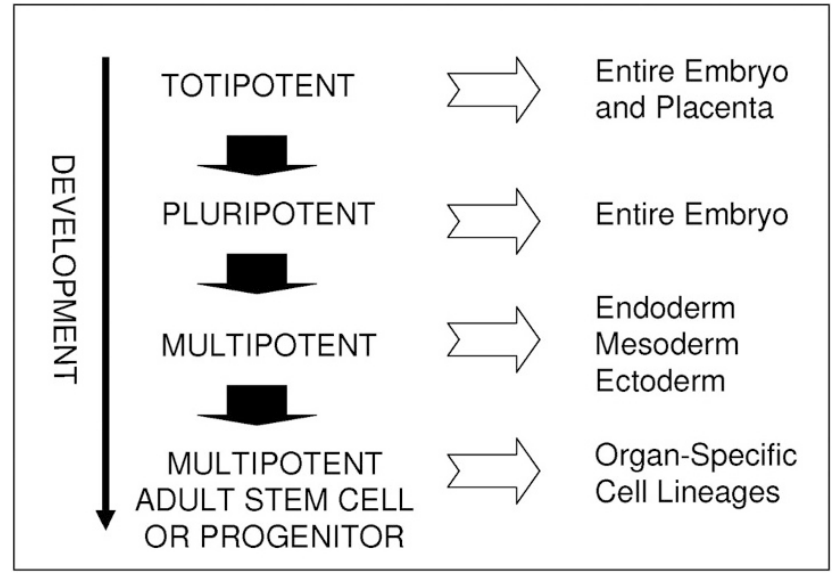

Figure 1. Simplified scheme of the relationship between development and stem cell potential.

cell mass of early blastocysts and retain the capacity to contribute to all three germ layers, whereas adult stem cells are restricted in their potential for generating various differentiated cell phenotypes.

Adult stem cells are slow-cycling undifferentiated cells $(4,5)$. These cells can undergo asymmetric division giving rise to daughter cells, one of which can be committed to differentiation and the other retaining the renewal capacity of the original stem cells. Studies performed largely in skin and small intestine have given rise to the concept of a classical stem cell hierarchy in which adult stem cells serve as the source of transit amplifying (TA) cells that cycle more rapidly but have more limited renewal capacity and exhibit more differentiated functions. TA cells contribute much of the increase in cell number that occurs in the steady state, eventually becoming incapable of proliferation and giving rise to cells that enter the terminally differentiated compartment. As a result of their slow-cycling phenotype, stem cells have been identified by their prolonged retention of nucleotide analogs such as bromodeoxyuridine (BrdU), and accordingly are referred to as label-retaining cells (LRCs).

\section{THE CONCEPT OF THE NICHE}

Adult somatic stem cells are thought to exist in a specialized environment called a "niche." The niche is further thought to provide the necessary environmental signaling that interacts with intrinsic factors within stem cells that act in concert to determine "stemness." These interactions maintain stem cells by balancing self-renewal against differentiation. The importance of this balance is well illustrated by the recognition that failure in its maintenance leads to cancer on the one hand, and organ failure on the other.

Much of the evidence for existence of a stem cell niche has come from identification of germline stem cells (GSCs) in Drosophila and C. elegans (6). In mammals, the bulk of the information has emerged from detailed studies of tissues with high rates of proliferation and turnover such as the intestine and the hair follicles. The initial identification of the niche has been in large part due to the ability of stem cells to retain mitotic labeling for prolonged periods $(7,8)$. However, re- cently, molecular markers such as CD34 and specific cell adhesion molecules such as $\alpha$-6-integrins also have been used to identify niches (9). Adhesion molecules in particular are thought to be central to the process of niche-stem cell interactions (10). It is of interest that a number of the molecules implicated in the maintenance of stem cells within the niche have demonstrated roles in lung development.

\section{LUNG MORPHOGENESIS AND STEM CELL BIOLOGY}

The lungs are derived from at least two sources of distinct cellular origins, endoderm and mesoderm. The progenitor of the pulmonary epithelium is the endoderm that is specified within a distinct region of the anterior foregut. The molecular mechanisms for lung specification are currently not well understood. Once specified, the process does not appear to be irreversible since over-expression of a constitutively active beta-Catenin-LEF-1 fusion protein, which is known to activate the WNT canonical pathway (please see below) results in reprogramming of the lung endoderm as evidenced by expression of markers for gut endoderm, the embryonic tissue from which it is originally derived (11). The lung primordium is thought to consist of a cluster of progenitor cells from which numerous differentiated epithelial cell types in the mature lung, including, but not limited to alveolar type I, and type II, Clara, basal and ciliated cells are derived (Fig. 2). In this way, the lung primordium can be viewed as a pool of multipotent cells with the capacity to generate multiple cell lineages found in the mature organ. Whether the pool consists of a group of homogeneous multipotential cells, or cells that are already

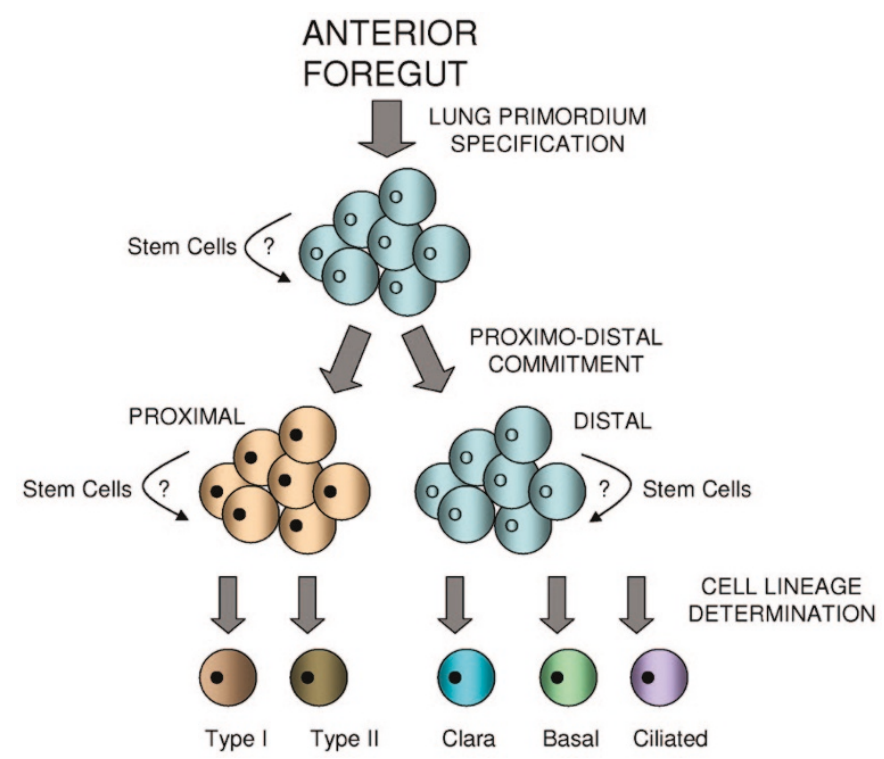

Figure 2. A simplified schematic representation of lung endodremal morphogenesis. The lung primordium is specified within the anterior foregut. It is not known whether at this point the cells are developmentally equal. Stem cells may emerge at this point, but become developmentally more restricted by localization in proximal versus distal niches as lung morphogenesis proceeds. Proximo-distal commitment occurs early during lung development resulting in emergence of distinct cell lineages, some of which are depicted here. The possibility that distinct stem cells emerge during the proximo-distal commitment also exists. 
committed along specific, albeit multiple cell lineages, remains unknown. Perl et al. (12) found that specification of the proximal versus distal lung compartments occurs very early during embryonic lung development suggesting that some differentiation occurs perhaps immediately subsequent to specification of the primordium. In the larval tracheal system of the fruit fly Drosophila, the entire individual organ is derived from a primordium that consists of a cluster of eighty presumably homogeneous ectodermal cells (13).

An important player in morphogenesis of the mammalian lung is the mesodermally-derived splanchnic mesenchyme. Growth and differentiation of the lung endoderm is strictly dependent on signaling from the mesenchyme. Classical recombination experiments mixing lung endoderm with distal versus proximal lung mesenchyme showed that the mesenchyme provides instructional cues for endodermal morphogenesis and cell lineage determination (14). It is important to note that the mesenchyme is also a source of cells contributing to a number of functional compartments in the lung including the vasculature and the airway smooth muscle. The focus of the current discussion will be on the lung endoderm about which more information is currently available.

Owing largely to analysis of various genetically manipulated mice, we now have some information about the molecules that figure importantly in lung cell proliferation and differentiation These molecules can be grouped into three broad functional categories: 1) signaling molecules, 2) transcription factors, and 3) extracellular matrix proteins and their receptors (15-18). The signaling molecules category is most relevant to the areas of overlap between morphogenesis and stem cell biology. Of these the three signaling pathways, WNT, SHH and BMP play major roles in both processes.

The WNT pathway. WNTs are cysteine-rich secreted glycoproteins that are vertebrate homologues of Drosophila wingless. The WNT pathway is complex consisting of at least 18 ligands, and 10 receptors, known after their Drosophila counterparts as Frizzled (Fzd) (19). At least three intracellular pathways mediate WNT signaling (20,21). The "canonical pathway" works through stabilization of $\beta$-catenin. The "noncanonical," $\beta$-catenin independent pathway is mediated through activation of protein kinase $\mathrm{C}$ (PKC) $(22,23)$, or c-jun N-terminal kinase (JNK) (24). Two functional features of the WNT pathway are of special interest to stem cell biology. First, members of the WNT family have distinct expression patterns in the embryo and adult organisms and are critical for regulation of tissue differentiation and organogenesis (www. stanford.edu/rnusse/Wntwindow.html). Second, and more importantly, WNT ligands are critical regulators of cell proliferation and some, including WNT1, WNT3a, WNT7a, and WNT8 exhibit transforming ability in mammalian cells (19). In addition, purified WNT3a protein was shown to induce self-renewal of hematopoietic stem cells (HSCs) (25) and WNT2b/WNT13 functions to maintain undifferentiated progenitor cells in ciliary marginal zone of the vertebrate retina (26). Thus, the canonical pathway appears to control stem cell activation, fate determination and differentiation.

A key factor in the canonical WNT pathway is the molecule known as adenomatous polyposis coli (APC). This molecule was initially identified as the product of a cancer suppressor gene lost during the development of colonic carcinomas with a putative role in regulating cellular proliferation (27). APC interacts directly with microtubules to establish epithelial cell polarity during mitosis (28). In Drosophila, APC is an important factor in regulating and maintaining the homeostatic balance between stem cell division and commitment of daughter cells to differentiation (29). Therefore, a potential underlying cause of neoplastic transformation in epithelial carcinomas, which can arise through an imbalance between self-renewal and differentiation commitment (increased cell proliferation) may be mutations in, or aberration of APC gene expression (30). This model of carcinogenesis has been recently invoked following the identification of a bronchoalveolar stem cell (BASC) population that responds to injury and K-ras-induced oncogenesis (31). Overall, the data from various sources are consistent with a role for WNT signaling in favoring stem cell proliferation in the self-renewal/differentiation balance within the niche.

In the lung, two members of the WNT family have been shown to play key roles during embryonic development. We have shown that WNT5a controls lung branching morphogenesis and maturation by interacting with SHH and FGF10 (32,33). A critical role in regulation of mesenchymal proliferation and vascular development has been described for WNT7b in lung development (34). In addition, WNT signaling through the canonical pathway participates in morphogenesis of submucosal glands in airway epithelium (35). Activation of the canonical pathway leads to nuclear localization of $\beta$-catenin and its interactions with transcription factors of the TCF/LEF family, which in turn regulate target gene transcription. LEF-1 is required for development of airway submucosal glands and LEF-1 mRNA is expressed in the glandular buds at early stages of development (35). In addition, the LEF-1 promoter can be induced by Wnt3a and a Wnt-responsive element in the LEF-1 promoter is required for LEF-1 expression in submucosal gland buds $(36,37)$. Given that submucosal gland duct cells have been identified as potential stem cells for regeneration of airway surface epithelium as well as submucosal glands (see below), these findings suggest a potential role for involvement of the $\mathrm{WNT} / \beta$-catenin/LEF/TCF pathway in stem cell maintenance in the airway epithelium.

The sonic hedgehog pathway. Both WNT and Sonic hedgehog $(\mathrm{SHH})$ are lipid-modified proteins and their signaling mechanisms at the cell surface show many similarities (38). SHH is the mammalian ortholog of Drosophila Hedgehog $(\mathrm{HH})$ and is highly expressed in the developing pulmonary epithelium (39). SHH signaling is mediated through its receptor Patched (PTC), a twelve transmembrane protein, and is transduced to changes in target gene regulation via the activity of the transcription factors Gli $(40,41)$. The role of $\mathrm{SHH}$ signaling in morphogenesis of the lung as well as in stem cell biology has been a target of investigation. During lung development, $\mathrm{SHH}$ is primarily made by the epithelium. PTC, on the other hand is expressed abundantly on the mesenchyme and receives and implements $\mathrm{SHH}$ signaling to pattern branching morphogenesis (39). Deletion of $\mathrm{SHH}$ signaling in the lung results in gross abnormalities with little evidence of 
cellular differentiation. In contrast, overexpression of $\mathrm{SHH}$ causes increased proliferation and perturbation of cellular differentiation. Based on the latter properties, SHH may be a strong candidate as a potential player in lung stem cell maintenance. In support of this model, transient activation of SHH was documented in the airway epithelium of adult lung during repopulation of injured airways in response to acute proximal injury (42). The latter observation suggests, but does not prove that activation of SHH may drive epithelial cell proliferation during repair of injury. Aberrant activation of SHH pathway, in which subverted stem cells express both SHH and PTC and thus escape the control mechanisms of the niche, has been proposed as a novel mechanism for pulmonary carcinogenesis (43). It is noteworthy that persistent activation of SHH signaling has been found in a subset of small cell lung carcinomas, consisting of neuroendocrine cells (42). The SHH pathway is active in the progenitors of neuroendocrine cells during lung development (42). Thus, it is tempting to speculate that uncontrolled growth of tumor cells may be explained by persistent activation of a signaling pathway such as SHH that would otherwise maintain the balance between proliferation and differentiation of stem cells within a niche (Fig. 3).

In both Drosophila and vertebrates, regulation of WNT and Hedgehog are linked. In Drosophila, the two signaling pathways interact during gastrulation and germ band extension. Hedgehog stimulates WNT in the adjacent cells and WNT functions to maintain engrailed (en), which controls the expression of Hedgehog $(41,44,45)$. In vertebrates, WNT2 expression appears to be dependent on SHH since it is decreased in $S h h(-/-)$ lungs (46). We have found that SHH is negatively regulated in the lung by WNT5a, a noncanonical Wnt (47) that antagonizes the activity of canonical WNTs such as WNT1 and WNT3a $(48,49)$. Absence of WNT5a results in increased expression of SHH and PTC (32), and overexpression of WNT5a leads to decreased expression of SHH



Figure 3. SHH pathway is implicated in stem cell maintenance and carcinogenesis. During morphogenesis, epithelial-mesenchymal interactions occur through paracrine $\mathrm{SHH}$ signaling between the two tissues, or compartments (A). In response to injury, intra-epithelial activation of $\mathrm{SHH}$ pathway was observed, suggesting that epithelial-epithelial paracrine signaling may underlie the mechanisms of cellular repopulation in injured airways $(B)$. Small cell lung cancer also manifests paracrine $\mathrm{SHH}$ signaling through expression of both ligand and receptor $(C)$, wherein there is distinct compartmentalization of signaling and receiving cells, similar to development $(A)$ and repair $(B)$. and PTC (33). Importantly, interaction between WNT and SHH plays a critical role in regulating progenitor cell behavior in tissues such as neural subventricular zone (SVZ) (50).

The bone morphogenetic protein pathway. Bone morphogenetic proteins (BMPs) are multifunctional signaling molecules in the TGF- $\beta$ superfamily that regulate a vast array of cellular processes, including proliferation, differentiation, apoptosis, adhesion, and migration (51). As other members of the TGF- $\beta$ pathway, BMPs act through cell surface receptors to activate a family of transcription factors known as SMADs. BMPs play key roles during embryonic development and remodeling and repair of tissue, wound healing, and inflammatory responses (52). Stem cell behavior within the niche is known to be regulated by BMPs. The most direct evidence for involvement of BMP signaling in regulation of self-renewal and differentiation of stem cells within a niche comes from the studies on Drosophila ovaries (53). In this system, the niche provides BMP signaling for maintenance of GSCs. The product of the gene Bam, on the other hand promotes differentiation of GSCs. Thus, it is likely that functional and opposing interactions between Bam and Bmp may constitute the molecular basis for maintenance of homeostasis within the ovarian niche. In support of this hypothesis, BMP signaling was found to directly repress Bam transcription in GSCs. These observations demonstrate that niche signaling directly represses differentiation-promoting genes in stem cells to maintain stem cell self-renewal status (53). In mammals, the critical role of BMP signaling has been demonstrated (54). In the adult mouse SVZ, large numbers of new neurons are born continuously. BMPs potently inhibit neurogenesis both in vitro and in vivo. The BMP antagonist Noggin is expressed by ependymal cells adjacent to the SVZ. Noggin promotes the creation of a neurogenic environment by blocking endogenous BMP signaling (54). Coincident with the roles of BMP and WNT signaling in stem cell biology, these two pathways are functionally closely related. Not only is WNT signaling required for activation of BMP4 $(55,56)$, WNT and BMP4 can synergistically activate target genes such as Msxl (57). Furthermore, mediators of WNT signaling, including beta-catenin and LEF-1/Tcf transcription regulators, physically and functionally interact with Smad4, a downstream component of TGF- $\beta$ superfamily pathway, and synergistically regulate expression of genes during formation of Spemann's organizer in Xenopus (58).

In the lung, although no direct evidence for the involvement of BMP signaling in the maintenance of lung stem cells is currently available, its expression in both mesenchymal and epithelial compartments suggests that this signaling pathway may indeed be critical for maintenance and activation of stem cells within pulmonary niches. BMP-5 \& BMP7 are expressed ubiquitously in the mesenchyme and epithelium of the lung respectively (59). BMP-4 is confined to the lung epithelium and is a major participant in lung distal morphogenesis. Targeted disruption of BMP-4 results in embryonic lethality before E10, indicating the essential role of this signaling molecule in early embryogenesis $(60,61)$. Lung-specific suppression of BMP-4, through over-expression of noggin, a secreted BMP-4 antagonist, or a dominant negative form of 
the BMP-4 type I receptor, Alk6, does not alter the differentiation of proximal lung cells as evidenced by expression of Clara cell specific markers, but reduces the number of differentiated alveolar type II (AT2) cells (62). Therefore, if BMP-4 figures importantly in lung stem cell maintenance and specification of the environment of the niche, its effect may be confined to distal lung.

\section{INTRAPULMONARY STEM CELLS}

Proximal versus distal niches. In the mature lung, there are estimates for the existence of over 40 distinct cell types organized into distinct anatomical regions along the proximodistal axis of the lung. The epithelium of the conducting airways is composed of ciliated, secretory, basal and other specialized cell types $(63,64)$. Quite distinct from these cells are the epithelial cells lining the alveolar compartments in the distal lung, such as alveolar epithelial type II (AT2) and type I (AT1) cells. As discussed above, it is generally believed that resident tissue-specific stem cells become established during embryogenesis and remain important for repair of selfrenewing tissues in the adult. However, the anatomic and histologic complexity of the lung and cellular quiescence in the basal state together with a paucity of specific markers for definitive identification of a stem cell phenotype have considerably impeded characterization of endogenous lung stem cells. Differences in the regional composition of airway cell populations between rodents and humans have further complicated this issue and our understanding of the role of resident lung stem cells in tissue maintenance and repair remains rudimentary.

Using the BrdU labeling approach to identify stem cells, as well as more recently developed surface markers, putative stem cells have been localized to specific sites (niches) throughout the conducting airways and distal lung epithelium $(3,65,66)$. An important question relates to whether there are distinct stem cells embedded within the proximal versus distal compartments of the lung. Evidence suggests that multipotent progenitors of the conducting airways (proximal) and gas- exchange regions (distal) of the lung are derived from distinct populations of cells whose lineage fate is determined relatively early during development (12). Consistent with early specification of either a proximal or distal fate, no single stem cell that can give rise to all lung epithelial cell types has been identified in the postnatal lung. However, a possible exception may be a recently identified population of BASCs discussed below that co-express markers of both proximal and distal lineages although their differentiation potential in vivo remains to be determined (31). In the adult lung, there appear to be distinct niches in the proximal and distal conducting airways harboring epithelial progenitor cells with different proliferative potential (Table 1).

The tracheobronchial niches. The major cell types constituting the pseudostratified epithelium of the tracheobronchial airways are basal cells, mucous secretory (goblet) cells and ciliated cells. In the proximal conducting airways of the mouse, cells that reside in the ducts of submucosal glands, basal cells and nonciliated secretory cells have been shown to proliferate and to contribute to repopulation of the airway epithelium (67-70). However, there has been lack of consensus on the exact differentiation capacity of each cell type and the degree to which each cell type is capable only of selfrenewal $(69,71)$. Several early studies suggested that basal cells function as multipotent progenitors capable of giving rise to all major tracheal epithelial cell types $(68,69,72-75)$. However, following mild NO2 injury basal cell proliferation was not significantly increased and regeneration of airway epithelium was carried out by secretory cells (70). Clonal analysis of retrovirally-tagged airway surface epithelial cells identified multiple progenitors with either limited or multipotent differentiation capacity (76). The type and degree of airway injury therefore seems to be an important determinant of specific activation of progenitor cell populations. Furthermore, the specific criteria used to determine stemness are key to determining whether cells participating in airway regeneration are truly stem cells capable of giving rise to all cell types, or

Table 1. Putative stem cell niches in mouse lung



BASC, Bronchioalveolar stem cells; vCE:variant, CCSP expressing cells.

* Although identified by different means, BASCs may be the same as vCE at BADJ.

** It is not clear if type II cells are true stem cells or function as a transit amplifying (TA) population. 
whether they are progenitors with more limited differentiation potential more closely resembling TA cells.

Polidocanol or $\mathrm{SO} 2$ can be used in an injury model to stimulate cell division in the normally quiescent tracheal epithelium of mice. Using this approach, Borthwick et al. (77) identified niches of keratin-rich LRCs in the ducts of submucosal glands in the upper trachea and at foci near the cartilageintercartilage junctions in association with neuroepithelial bodies (NEBs). The ratio of basal to columnar LRCs in the distal trachea was 2:1. Tracheal xenografts in which surface epithelium was removed by protease digestion could be reepithelialized from submucosal gland remnants following transplantation into nude mice, supporting the notion that submucosal gland ducts may serve as a stem cell niche. LRCs did not express the neuroendocrine marker calcitonin generegulated peptide (CGRP) but small numbers of pulmonary neuroendocrine cells (PNECs) localized to LRC niches suggesting that PNECs, while not themselves precursors for regeneration of airway epithelium, may contribute to the niche microenvironment. These results are consistent with previous studies using retroviral lineage tracing in adult human proximal airway in which a subset of pluripotent cells was identified with the capacity for both glandular and surface airway epithelial differentiation, although the identity of the putative stem cells, tagged by this approach could not be determined (76).

To examine the clonal potential of tracheal basal cells, the keratin 5 (K5) promoter, which is active in niches of LRC in mouse trachea, was used to drive expression of enhanced green fluorescence protein (EGFP) specifically in a subset of basal cells in transgenic mice, corresponding generally to the pattern of LRCs observed in a previous study (78). Examination of sorted populations identified 4.5-fold greater colony forming efficiency in EFGP-positive cells (i.e. within the basal cell compartment) than within the EGFP-negative fraction. A small number of cells that were highly enriched for K5 were able to give rise to large colonies. Examination of colonies revealed expression of Clara cell specific protein (CCSP) and $\beta$-tubulin 4 (ciliated cell marker) consistent with differentiation to both secretory and ciliated cell types respectively, indicating clonogenicity and multi-lineage differentiation capacity of this subset of basal cells. The subset of K5- expressing cells capable of generating large colonies may represent a population of airway stem cells; however, whether these K5-expressing cells absolutely co-localize with the LRC compartment or represent part of the TA population has not been definitively established.

Lineage tagging using a Cre-loxP reporter approach was used in conjunction with in vivo Clara cell depletion to investigate repair of injured mouse tracheal epithelium and address specifically the contribution of basal cells to tracheal regeneration (79). Cytokeratin 14 (K14) is highly expressed within a subpopulation of tracheal basal cells. The K14 promoter was therefore used to drive expression of Cre, which, following recombination, led to expression of LacZ in a subset of tracheal basal cells. Subsets of K14-expressing cells were capable of multipotent or unipotent differentiation in vivo, giving rise to basal, ciliated and Clara cells or only basal cells, respectively. In a separate study using a similar approach, basal cells were identified as being capable of multipotent progenitor repopulation of bronchial epithelium (79). The airway epithelium has a high degree of plasticity which could account for previous observations from this group and others demonstrating that both basal and nonbasal cells could regenerate a complete mucociliary epithelium $(70,71)$. The relative contributions of basal cells versus submucosal gland cells under different conditions of injury remains to be absolutely determined. The ability to track the fate of specific progenitor cells using cell-specific promoters to permanently label cells as well as development of better specific surface markers for the stem cell phenotype will be key to determining the differentiation potential of putative regional stem cells.

The bronchiolar niches. The terminal bronchioles are lined with simple epithelium composed of ciliated and non-ciliated cells which include Clara cells (64). Clara cells appear to be capable of self-renewal and of differentiation into ciliated cells, functioning as the major TA population within the bronchiolar epithelium after oxidant-mediated damage $(70,80,81)$. Clara cells have the capacity to metabolize lipophilic compounds through cytochrome P450-mediated oxidation, making them susceptible to injury by such compounds (82). Depletion of Clara cells by administration of the Clara cell-specific cytotoxicant, naphthalene, fails to diminish the regenerative potential of terminal bronchioles indicating the presence of pollutant resistant stem cells that are able to participate in airway regeneration after TA cell depletion (83).

In the bronchiolar epithelium, the NEB has been identified as a unique microenvironment harboring progenitor cells capable of restoring airway epithelium after injury of pollutantsensitive Clara cells (83). Consistent with the existence of a stem cell pool in the NEB microenvironment, Reynolds et al. (83) demonstrated that depletion of the TA (Clara cell) pool with naphthalene results in activation of two proliferative populations within the NEB microenvironment, namely PNECs and CCSP-IR Clara cells. Subsets of CCSP-expressing cells located within NEBs appear to have different characteristics from classical Clara cells in that they express lower levels of CCSP, are deficient in the phase I xenobiotic enzyme CYP-2F2, and appear to be relatively resistant to naphthalene suggesting that they may represent a stem cell pool (83). This resistant population of cells has been termed variant CCSPexpressing (vCE) cells. The relative contributions of PNEC and CCSP-expressing cells to epithelial regeneration was further investigated by ablation of CCSP-expressing cells using a model in which the CCSP promoter drives expression of the herpes simplex virus thymidine kinase (84). Ablation of CCSP-expressing cells by administration of gancyclovir led to failure of regeneration of the airway epithelium despite proliferation/hyperplasia of PNECs indicating a requirement of naphthalene resistant vCE cells for regeneration of airway epithelium after TA cell depletion. These studies indicate that although PNECs proliferate in response to naphthalene, they are not sufficient for regeneration of airway epithelium. Similar pollutant-resistant vCE have been identified in terminal bronchioles associated with the bronchoalveolar duct junction (BADJ) (85). Despite the identification within bronchiolar 
epithelium of these two niches of naphthalene-resistant $\mathrm{vCE}$ cells, the complexity of this issue is highlighted by the recent suggestion that ciliated cells, previously considered to be terminally differentiated, are able to undergo squamous metaplasia and re-differentiate into cuboidal and columnar cell types to restore the bronchiolar epithelium following naphthalene injury (86). Although not definitively proven by lineage tagging of ciliated cells, these results illustrate the difficulty in distinguishing the relative contributions of stem cells versus progenitors with more limited differentiation capacity to airway regeneration under different conditions of injury.

A population of cells that co-express CCSP and surfactant protein C (SP-C), markers of Clara cells and AT2 cells, respectively, and originally identified in K-ras-expressing lung tumors was recently identified at the BADJ, a putative stem cell niche in normal lung (31). These cells were resistant to bronchiolar and alveolar damage induced by naphthalene and bleomycin respectively, proliferated during epithelial cell renewal in vivo, underwent clonal colony formation, exhibited extensive self-renewal in culture and were multipotent in clonal assays. When grown on Matrigel, colonies gave rise to cells expressing CCSP, SP-C and aquaporin-5 (a marker of AT1 cells). Although difficult to identify morphologically as Clara or AT2 cells, these findings suggested that these doublepositive cells may represent a stem cell population for Clara cells and alveolar epithelial cells. Based on these properties, the cells were named BASCs. By FACS analysis, CCSP+ SP-C + BASCs were identified within the $S_{c a}{ }^{+} \mathrm{CD}_{4} 5^{-}$ $\mathrm{PECAM}^{-}$population. Within the $\mathrm{Sca} \mathrm{I}^{+} \mathrm{CD}^{-} 5^{-} \mathrm{PECAM}^{-}$population, the $\mathrm{CD}_{3} 4^{+}$population was enriched for $\mathrm{CCSP}^{+}$ $\mathrm{SP}_{-} \mathrm{C}^{+}$positive cells. Further immunostaining confirmed $\mathrm{ScaI}^{+} \mathrm{CCSP}^{+} \mathrm{Cd}_{3} 4^{+}$cells that were $\mathrm{CD}_{4} 5^{-}$exclusively at the BADJ. The observation that these cells expanded in response to oncogenic K-ras in vitro and in precursors of lung tumors in vivo, suggested this stem cell population may also be putative precursor cells for adenocarcinomas demonstrating the importance of the appropriate balance between differentiation and proliferation for maintaining the normal composition of airway cell populations. Based on their location and expression of CCSP, these cells likely represent the same population as vCE identified previously at the BADJ (87).

The alveolar niches. The alveolar epithelium consists of two morphologically distinct cell types, AT1 and AT2 cells $(88,89)$. AT2 cells are cuboidal and surfactant-producing whereas AT1 cells are larger squamous cells with long cytoplasmic processes that cover the majority of the gas exchange surface of the lung $(90,91)$. AT2 cells are capable of selfrenewal and have been thought to serve as progenitors for repair of distal lung epithelium during normal maintenance and repair following injury, whereas AT1 cells in vivo have been considered to be terminally differentiated $(92,93)$. Studies of oxygen toxicity in monkeys led to the suggestion that AT2 cells may serve as progenitors for replacement of AT1 cells (94). The concept of the AT2 cells as progenitor was further investigated by serial analyses of thymidine incorporation using light and electron microscopy combined with autoradiographic techniques following exposure to $\mathrm{NO} 2$ $(92,95)$. Tritiated thymidine first appeared in AT2 cells fol- lowed by appearance of label in AT1 cells. Labeled Cells with an intermediate phenotype also were identified suggesting that AT2 cells served as the progenitors for AT1 cells. Similar studies following oxygen exposure in mice (93) also suggested transition from AT2 to AT1 cell following injury. Whether this transition can occur in vivo without an intervening cell division has not been determined. The differentiated characteristics of AT2 cells together with rapid proliferation following injury suggests that AT2 cells more closely resemble those of a TA cell than a true stem cell population. Subpopulations of AT2 cells that are more resistant to injury have been identified (96). The possible existence of other as yet unidentified, undifferentiated distal lung cells that can give rise to either or both AT1 and AT2 cells has not been ruled out, while the relative contribution of BASCs to differentiated alveolar epithelium in vivo remains to be determined.

Similar to observations in vivo, isolated AT2 cells in primary culture lose their phenotypic hallmarks and gradually acquire the morphologic features of AT1 cells $(97,98)$. The cells increasingly express all available AT1 cell phenotypic markers suggesting that AT2 cells in vitro transdifferentiate toward an AT1 cell phenotype (AT1-like cells) (99-101). Experimental conditions have been developed that promote retention of the AT2 cell phenotype (e.g., culture with rat serum, with keratinocyte growth factor or on contracted gels) $(99,100,102)$. Importantly, cells that have transdifferentiated toward an AT1 cell-like phenotype can be induced to reexpress the phenotypic characteristics of AT2 cells, suggesting far greater plasticity in expression of the differentiated alveolar epithelial cell phenotypes than believed from previous in vivo studies. Whether AT1 cells in vivo are capable of such reversible transdifferentiation, perhaps enabling them to contribute to the proliferative pool of progenitors following injury has not yet been determined.

Side populations. Side population (SP) cells are rare cells defined by their ability to exclude Hoechst 33342 dye via the action of cell-surface-localized ATP binding cassette (ABC) half-transporter breast cancer resistance protein (BRCP1), and are highly enriched for stem cell activity $(103,104)$. BRCP1 (-/-) mice have a normal number of HSCs indicating that while BRCP1 is a marker of SP cells, it is not required for stem cell function (105). BM SP cells express the stem cell markers Sca-1 and c-kit, and lack expression of mature hematopoietic lineage markers (Lin-). BM-derived SP reconstitute lethally irradiated mice in smaller numbers than whole $\mathrm{BM}$ and may also have the capacity to reconstitute nonhematopoeitic tissues (e.g. skeletal muscle, cardiac muscle, vascular endothelium and liver $(106,107)$. The property of Hoechst efflux (SP phenotype) has been used in an attempt to identify stem cells from organs other than BM. Using this approach, SP cells have been identified in a variety of nonhematopoeitic tissues such as skeletal muscle, liver, kidney and lung and share phenotypic characteristics with BM SP cells $(108,109)$. In contrast to BM SP, tissue SP are characterized by heterogeneity in expression of CD45 which varies between tissues. Asakura and Rudnicki (110) first demonstrated that whole lung tissue gave rise to hematopoeitic colonies and determined that the hematopoietic ability resided in the $\mathrm{CD} 45^{+}$fraction 
but only gave rise to granulocytic and monocytic colonies. Summer et al. (111) demonstrated that mouse lung SP cells constitute $0.03-0.07 \%$ of total lung cells and characterized their surface phenotype as $\mathrm{ScaI} \mathrm{I}^{+}, \mathrm{BRCP} 1^{+}, \mathrm{Lin}^{-}$and heterogeneous at the CD45 locus (75\% CD45-positive). However, SP cells could not be localized by immunostaining for BRCP1 because of the rarity of the SP cells as well as the lack of correlation of expression with function. Lung SP cells express hepatocyte nuclear factor-3 $\beta$ (HNF-3 $\beta$ ) but not NKX2.1, two critical transcription factors in the lung epithelium. To further define the origin of lung SP cells, transplantation studies were performed in which wild type BM was transplanted into BRCP1-deficient mice (which do not have an identifiable SP population) or GFP-expressing BM or SP cells were transplanted into wild-type mice. 6-8 mo. post-transplantation SP were identified in similar numbers as in wild type animals. Both $\mathrm{CD} 45^{+}$and $\mathrm{CD} 45^{-}$cells were present in the SP gate suggesting that lung SP are BM-derived (112). There was heterogeneity in expression of SMA and cytokeratin suggestive of subpopulations of cells with differing potential for differentiation. $\mathrm{CD} 45^{+}$lung SP cells express PU.1 a transcription factor characteristic of myeloid progenitors, suggesting that the $\mathrm{CD} 45^{+}$fraction serves as local progenitors for myeloid cells in the lung. The fate of tissue CD45 ${ }^{-} \mathrm{SP}$ cells is less clear although recent gene profiling studies of embryonic CD $45^{-}$SP cells identified several genes associated with an endothelial phenotype consistent with a role in vascular development (113). Giangreco and colleagues (87) evaluated SP from elastase digested lungs which were enriched for cells expressing airway-specific markers. In contrast to the findings of Summer et al. (112), Sca-1 reactivity was enriched among $\mathrm{CD} 45^{-}$SP cells and was not unique to SP cells. Furthermore, CD45 ${ }^{-}$SP cells included cells expressing vimentin and CCSP, consistent with the presence of mesenchymal cells and conducting airway cells in this fraction. Presence of CCSP, coupled with absence of CYP450-2F2, suggests enrichment within this SP for vCE identified by other methods as bronchiolar stem cells as discussed above. The apparent discrepancies among the studies may reflect differences in methods used for enzymatic dissociation of lung tissue which likely sampled different cellular compartments, as well as variability in FACS analysis. Further characterization of these SP populations using standardized approaches for isolation and sorting is needed to understand their exact differentiation potential and the functional contribution of this heterogeneous population to tissue homeostasis and repair following lung injury.

\section{THERAPEUTIC POTENTIAL OF ADULT STEM CELLS}

The progressive nature of a number of pediatric and adult lung diseases (e.g. pulmonary fibrosis, emphysema, acute respiratory distress syndrome and bronchopulmonary dysplasia) suggests an inadequate response of normal regenerative pathways following lung injury. It has been suggested that such diseases reflect a stem cell failure possibly due to either absolute loss of stem cells or disruption of the niche or both. Several putative stem cells located in specific niches have been identified within the conducting airways and distal lung epithelium. However, little is known of their molecular phenotype or the factors that regulate their properties. Characterization of somatic stem cell populations within the lung and the factors that determine stemness will be critical to augmenting their proliferative potential and harnessing their capacity for differentiation along specific lineages to improve tissue regeneration. In particular, identification of key signals involved in maintenance of the stem cell niche as discussed above may allow modulation of the local environment to favor stem cell survival and regeneration. Obviously, any therapeutic approach will have to be balanced by the potential for unlimited proliferation and malignant transformation. In addition to the possibility of manipulating endogenous stem cells to augment local repair, intrapulmonary stem cells may be amenable to manipulation for treatment of genetic diseases (e.g. cystic fibrosis). Although these possible applications are intriguing, the true potential of endogenous stem cells as therapeutic targets remains to be determined.

\section{REFERENCES}

1. Griffiths MJ, Bonnet D, Janes SM 2005 Stem cells of the alveolar epithelium Lancet 366:249-260

2. Neuringer IP, Randell SH 2004 Stem cells and repair of lung injuries. Respir Res $5: 6$

3. Otto WR 2002 Lung epithelial stem cells. J Pathol 197:527-535

4. Watt FM, Hogan BL 2000 Out of Eden: stem cells and their niches. Science 287:1427-1430

5. Slack JM 2000 Stem cells in epithelial tissues. Science 287:1431-1433

6. Li L, Xie T 2005 Stem Cell Niche: Structure and Function. Annu Rev Cell Dev Biol 21:605-631

7. Cotsarelis G, Sun TT, Lavker RM 1990 Label-retaining cells reside in the bulge area of pilosebaceous unit: implications for follicular stem cells, hair cycle, and skin carcinogenesis. Cell 61:1329-1337

8. Potten CS, Owen G, Booth D 2002 Intestinal stem cells protect their genome by selective segregation of template DNA strands. J Cell Sci 115:2381-2388

9. Blanpain C, Lowry WE, Geoghegan A, Polak L, Fuchs E 2004 Self-renewal, multipotency, and the existence of two cell populations within an epithelial stem cell niche. Cell 118:635-648

10. Kubota H, Avarbock MR, Brinster RL 2003 Spermatogonial stem cells share some, but not all, phenotypic and functional characteristics with other stem cells. Proc Natl Acad Sci U S A 100:6487-6492

11. Okubo T, Hogan BL 2004 Hyperactive Wnt signaling changes the developmental potential of embryonic lung endoderm. J Biol 3:11

12. Perl AK, Wert SE, Nagy A, Lobe CG, Whitsett JA 2002 Early restriction of peripheral and proximal cell lineages during formation of the lung. Proc Natl Acad Sci U S A 99:10482-10487

13. Metzger RJ, Krasnow MA 1999 Genetic control of branching morphogenesis. Science 284:1635-1639

14. Spooner BS, Wessells NK 1970 Mammalian lung development: interactions in primordium formation and bronchial morphogenesis. J Exp Zool 175:445-454

15. Cardoso WV 2001 Molecular regulation of lung development. Annu Rev Physiol 63:471-494

16. Demayo F, Minoo P, Plopper CG, Schuger L, Shannon J, Torday JS 2002 Mesenchymal-epithelial interactions in lung development and repair: are modeling and remodeling the same process? Am J Physiol Lung Cell Mol Physiol 283:L510_ L517

17. Chinoy MR 2003 Lung growth and development. Front Biosci 8:D392-D415

18. Warburton D, Schwarz M, Tefft D, Flores-Delgado G, Anderson KD, Cardoso WV 2000 The molecular basis of lung morphogenesis. Mech Dev 92:55-81

19. Wodarz A, Nusse R 1998 Mechanisms of Wnt signaling in development. Annu Rev Cell Dev Biol 14:59-88

20. Miller JR 2002 The Wnts. Genome Biol 2001, 3(1): reviews 3001.1-3001.15

21. Huelsken J, Birchmeier W 2001 New aspects of Wnt signaling pathways in higher vertebrates. Curr Opin Genet Dev 11:547-553

22. Kuhl M, Geis K, Sheldahl LC, Pukrop T, Moon RT, Wedlich D 2001 Antagonistic regulation of convergent extension movements in Xenopus by Wnt/beta-catenin and Wnt/Ca2+ signaling. Mech Dev 106:61-76

23. Mudher A, Chapman S, Richardson J, Asuni A, Gibb G, Pollard C, Killick R, Iqbal T, Raymond L, Varndell I, Sheppard P, Makoff A, Gower E, Soden PE, Lewis P, Murphy M, Golde TE, Rupniak HT, Anderton BH, Lovestone S 2001 Dishevelled regulates the metabolism of amyloid precursor protein via protein kinase $\mathrm{C} / \mathrm{mito}-$ gen-activated protein kinase and c-Jun terminal kinase. J Neurosci 21:4987-4995

24. Yamanaka H, Moriguchi T, Masuyama N, Kusakabe M, Hanafusa H, Takada R, Takada S, Nishida E 2002 JNK functions in the non-canonical Wnt pathway to regulate convergent extension movements in vertebrates. EMBO Rep 3:69-75 
25. Willert K, Brown JD, Danenberg E, Duncan AW, Weissman IL, Reya T, Yates JR, Nusse R 2003 Wnt proteins are lipid-modified and can act as stem cell growth factors. Nature 423:448-452

26. Kubo F, Takeichi M, Nakagawa S 2003 Wnt2b controls retinal cell differentiation at the ciliary marginal zone. Development 130:587-598

27. Senda T, Shimomura A, Iizuka-Kogo A 2005 Adenomatous polyposis coli (Apc) tumor suppressor gene as a multifunctional gene. Anat Sci Int 80:121-131

28. Mogensen MM, Tucker JB, Mackie JB, Prescott AR, Nathke IS 2002 The adenomatous polyposis coli protein unambiguously localizes to microtubule plus ends and is involved in establishing parallel arrays of microtubule bundles in highly polarized epithelial cells. J Cell Biol 157:1041-1048

29. Yamashita YM, Jones DL, Fuller MT 2003 Orientation of asymmetric stem cell division by the APC tumor suppressor and centrosome. Science 301:1547-1550

30. Brittan M, Wright NA 2004 Stem cell in gastrointestinal structure and neoplastic development. Gut 53:899-910

31. Kim CF, Jackson EL, Woolfenden AE, Lawrence S, Babar I, Vogel S, Crowley D, Bronson RT, Jacks T 2005 Identification of bronchioalveolar stem cells in normal lung and lung cancer. Cell 121:823-835

32. Li C, Xiao J, Hormi K, Borok Z, Minoo P 2002 Wnt5a participates in distal lung morphogenesis. Dev Biol 248:68-81

33. Li C, Hu L, Xiao J, Chen H, Li JT, Bellusci S, Delanghe S, Minoo P 2005 Wnt5a regulates Shh and Fgf10 signaling during lung development. Dev Biol 287:86-97

34. Shu W, Jiang YQ, Lu MM, Morrisey EE 2002 Wnt7b regulates mesenchymal proliferation and vascular development in the lung. Development 129:48314842

35. Duan D, Yue Y, Zhou W, Labed B, Ritchie TC, Grosschedl R, Engelhardt JF 1999 Submucosal gland development in the airway is controlled by lymphoid enhancer binding factor 1 (LEF1). Development 126:4441-4453

36. Driskell RR, Liu X, Luo M, Filali M, Zhou W, Abbott D, Cheng N, Moothart C, Sigmund CD, Engelhardt JF 2004 Wnt-responsive element controls Lef-1 promoter expression during submucosal gland morphogenesis. Am J Physiol Lung Cell Mol Physiol 287:L752-L763

37. Filali M, Cheng N, Abbott D, Leontiev V, Engelhardt JF 2002 Wnt-3A/beta-catenin signaling induces transcription from the LEF-1 promoter. J Biol Chem 277:3339833410

38. Nusse R 2003 Wnts and Hedgehogs: lipid-modified proteins and similarities in signaling mechanisms at the cell surface. Development 130:5297-5305

39. Bellusci S, Furuta Y, Rush MG, Henderson R, Winnier G, Hogan BL 1997 Involvement of Sonic hedgehog (Shh) in mouse embryonic lung growth and morphogenesis. Development 124:53-63

40. Mendelson CR 2000 Role of transcription factors in fetal lung development and surfactant protein gene expression. Annu Rev Physiol 62:875-915

41. Ingham PW 1998 Transducing Hedgehog: the story so far. EMBO J 17:3505-3511

42. Watkins DN, Berman DM, Burkholder SG, Wang B, Beachy PA, Baylin SB 2003 Hedgehog signalling within airway epithelial progenitors and in small-cell lung cancer. Nature 422:313-317

43. Watkins DN, Berman DM, Baylin SB 2003 Hedgehog signaling: progenitor phenotype in small-cell lung cancer. Cell Cycle. 2:196-198

44. Siegfried E, Wilder EL, Perrimon N 1994 Components of wingless signalling in Drosophila. Nature 367:76-80

45. Dominguez M, Brunner M, Hafen E, Basler K 1996 Sending and receiving the hedgehog signal: control by the Drosophila Gli protein Cubitus interruptus. Science 272:1621-1625

46. Pepicelli CV, Lewis PM, McMahon AP 1998 Sonic hedgehog regulates branching morphogenesis in the mammalian lung. Curr Biol 8:1083-1086

47. Kemp C, Willems E, Abdo S, Lambiv L, Leyns L 2005 Expression of all Wnt genes and their secreted antagonists during mouse blastocyst and postimplantation development. Dev Dyn 233:1064-1075

48. Topol L, Jiang X, Choi H, Garrett-Beal L, Carolan PJ, Yang Y 2003 Wnt-5a inhibits the canonical Wnt pathway by promoting GSK-3-independent beta-catenin degradation. J Cell Biol 162:899-908

49. Torres MA, Yang-Snyder JA, Purcell SM, DeMarais AA, McGrew LL, Moon RT 1996 Activities of the Wnt-1 class of secreted signaling factors are antagonized by the Wnt-5A class and by a dominant negative cadherin in early Xenopus development. J Cell Biol 133:1123-1137

50. Viti J, Gulacsi A, Lillien L 2003 Wnt regulation of progenitor maturation in the cortex depends on Shh or fibroblast growth factor 2. J Neurosci 23:5919-5927

51. Varga AC, Wrana JL 2005 The disparate role of BMP in stem cell biology. Oncogene 24:5713-5721

52. Hogan BL 1996 Bone morphogenetic proteins in development. Curr Opin Genet Dev 6:432-438

53. Song X, Wong MD, Kawase E, Xi R, Ding BC, McCarthy JJ, Xie T 2004 Bmp signals from niche cells directly repress transcription of a differentiation-promoting gene, bag of marbles, in germline stem cells in the Drosophila ovary. Development 131:1353-1364

54. Lim DA, Tramontin AD, Trevejo JM, Herrera DG, Garcia-Verdugo JM, AlvarezBuylla A 2000 Noggin antagonizes BMP signaling to create a niche for adult neurogenesis. Neuron 28:713-726

55. Kim JS, Crooks H, Dracheva T, Nishanian TG, Singh B, Jen J, Waldman T 2002 Oncogenic beta-catenin is required for bone morphogenetic protein 4 expression in human cancer cells. Cancer Res 62:2744-2748

56. Shu W, Guttentag S, Wang Z, Andl T, Ballard P, Lu MM, Piccolo S, Birchmeier W, Whitsett JA, Millar SE, Morrisey EE 2005 Wnt/beta-catenin signaling acts upstream of N-myc, BMP4, and FGF signaling to regulate proximal-distal patterning in the lung. Dev Biol 283:226-239
57. Willert J, Epping M, Pollack JR, Brown PO, Nusse R 2002 A transcriptional response to Wnt protein in human embryonic carcinoma cells. BMC Dev Biol 2:8

58. Nishita M, Hashimoto MK, Ogata S, Laurent MN, Ueno N, Shibuya H, Cho KW 2000 Interaction between Wnt and TGF-beta signalling pathways during formation of Spemann's organizer. Nature 403:781-785

59. King JA, Marker PC, Seung KJ, Kingsley DM 1994 BMP5 and the molecular, skeletal, and soft-tissue alterations in short ear mice. Dev Biol 166:112-122

60. Lawson KA, Dunn NR, Roelen BA, Zeinstra LM, Davis AM, Wright CV, Korving JP, Hogan BL 1999 Bmp4 is required for the generation of primordial germ cells in the mouse embryo. Genes Dev 13:424-436

61. Winnier G, Blessing M, Labosky PA, Hogan BL 1995 Bone morphogenetic protein- 4 is required for mesoderm formation and patterning in the mouse. Genes Dev 9:2105-2116

62. Weaver M, Yingling JM, Dunn NR, Bellusci S, Hogan BL 1999 Bmp signaling regulates proximal-distal differentiation of endoderm in mouse lung development. Development 126:4005-4015

63. McDowell EM, Barrett LA, Glavin F, Harris CC, Trump BF 1978 The respiratory epithelium. I. Human bronchus. J Natl Cancer Inst 61:539-549

64. Breeze RG, Wheeldon EB 1977 The cells of the pulmonary airways. Am Rev Respir Dis 116:705-777

65. Engelhardt JF 2001 Stem cell niches in the mouse airway. Am J Respir Cell Mol Biol 24:649-652

66. Bishop AE 2004 Pulmonary epithelial stem cells. Cell Prolif 37:89-96

67. Emura M, Ochiai A, Singh G, Katyal SL, Hirohashi S 1997 In vitro reconstitution of human respiratory epithelium. In Vitro Cell Dev Biol Anim 33:602-605

68. Inayama Y, Hook GE, Brody AR, Cameron GS, Jetten AM, Gilmore LB, Gray T, Nettesheim P 1988 The differentiation potential of tracheal basal cells. Lab Invest 58:706-717

69. Inayama Y, Hook GE, Brody AR, Jetten AM, Gray T, Mahler J, Nettesheim P 1989 In vitro and in vivo growth and differentiation of clones of tracheal basal cells. Am J Pathol 134:539-549

70. Evans MJ, Shami SG, Cabral-Anderson Dekker NP 1986 Role of nonciliated cells in renewal of the bronchial epithelium of rats exposed to NO2. Am J Pathol 123:126133

71. Liu JY, Nettesheim P, Randell SH 1994 Growth and differentiation of tracheal epithelial progenitor cells. Am J Physiol 266:L296-L307

72. Donnelly GM, Haack DG, Heird CS 1982 Tracheal epithelium: cell kinetics and differentiation in normal rat tissue. Cell Tissue Kinet 15:119-130

73. Breuer R, Zajicek G, Christensen TG, Lucey EC, Snider GL 1990 Cell kinetics of normal adult hamster bronchial epithelium in the steady state. Am J Respir Cell Mol Biol 2:51-58

74. Ford JR, Terzaghi-Howe M 1992 Basal cells are the progenitors of primary tracheal epithelial cell cultures. Exp Cell Res 198:69-77

75. Boers JE, Ambergen AW, Thunnissen FB 1998 Number and proliferation of basal and parabasal cells in normal human airway epithelium. Am J Respir Crit Care Med 157:2000-2006

76. Engelhardt JF, Schlossberg H, Yankaskas JR, Dudus L 1995 Progenitor cells of the adult human airway involved in submucosal gland development. Development 121:2031-2046

77. Borthwick DW, Shahbazian M, Krantz QT, Dorin JR, Randell SH 2001 Evidence for stem-cell niches in the tracheal epithelium. Am J Respir Cell Mol Biol 24:662-670

78. Schoch KG, Lori A, Burns KA, Eldred T, Olsen JC, Randell SH 2004 A subset of mouse tracheal epithelial basal cells generates large colonies in vitro. Am J Physiol Lung Cell Mol Physiol 286:L631-L642

79. Hong KU, Reynolds SD, Watkins S, Fuchs E, Stripp BR 2004 In vivo differentiation potential of tracheal basal cells: evidence for multipotent and unipotent subpopulations. Am J Physiol Lung Cell Mol Physiol 286:L643-L649

80. Evans MJ, Cabral-Anderson LJ, Freeman G 1978 Role of the Clara cell in renewal of the bronchiolar epithelium. Lab Invest 38:648-653

81. Nettesheim P, Jetten AM, Inayama Y, Brody AR, George MA, Gilmore LB, Gray T, Hook GE 1990 Pathways of differentiation of airway epithelial cells. Environ Health Perspect 85:317-329

82. Plopper CG, Suverkropp C, Morin D, Nishio S, Buckpitt A 1992 Relationship of cytochrome P-450 activity to Clara cell cytotoxicity. I. Histopathologic comparison of the respiratory tract of mice, rats and hamsters after parenteral administration of naphthalene. J Pharmacol Exp Ther 261:353-363

83. Reynolds SD, Giangreco A, Power JH, Stripp BR 2000 Neuroepithelial bodies of pulmonary airways serve as a reservoir of progenitor cells capable of epithelial regeneration. Am J Pathol 156:269-278

84. Hong KU, Reynolds SD, Giangreco A, Hurley CM, Stripp BR 2001 Clara cell secretory protein-expressing cells of the airway neuroepithelial body microenvironment include a label-retaining subset and are critical for epithelial renewal after progenitor cell depletion. Am J Respir Cell Mol Biol 24:671-681

85. Giangreco A, Reynolds SD, Stripp BR 2002 Terminal bronchioles harbor a unique airway stem cell population that localizes to the bronchoalveolar duct junction. Am J Pathol 161:173-182

86. Park KS, Wells JM, Zorn AM, Wert SE, Laubach VE, Fernandez LG, Whitsett JA 2006 Transdifferentiation of Ciliated Cells During Repair of the Respiratory Epithelium. Am J Respir Cell Mol Biol 34:151-157

87. Giangreco A, Shen H, Reynolds SD, Stripp BR 2004 Molecular phenotype of airway side population cells. Am J Physiol Lung Cell Mol Physiol 286:L624-L630

88. Crapo JD, Barry BE, Gehr P, Bachofen M, Weibel ER 1982 Cell number and cell characteristics of the normal human lung. Am Rev Respir Dis 126:332-337 
89. Haies DM, Gil J, Weibel ER 1981 Morphometric study of rat lung cells. I. Numerical and dimensional characteristics of parenchymal cell population. Am Rev Respir Dis 123:533-541

90. Williams MC 2003 Alveolar type I cells: molecular phenotype and development. Annu Rev Physiol 65:669-695

91. Kikkawa Y, Yoneda K 1974 The type II epithelial cell of the lung. I. Method of isolation. Lab Invest 30:76-84

92. Evans MJ, Cabral LJ, Stephens RJ, Freeman G 1975 Transformation of alveolar type 2 cells to type 1 cells following exposure to NO2. Exp Mol Pathol 22:142-150

93. Adamson IY, Bowden DH 1974 The type 2 cell as progenitor of alveolar epithelial regeneration. A cytodynamic study in mice after exposure to oxygen. Lab Invest 30:35-42

94. Kapanci Y, Weibel ER, Kaplan HP, Robinson FR 1969 Pathogenesis and reversibility of the pulmonary lesions of oxygen toxicity in monkeys. II. Ultrastructural and morphometric studies. Lab Invest 20:101-118

95. Evans MJ, Cabral LJ, Stephens RJ, Freeman G 1973 Renewal of alveolar epithelium in the rat following exposure to NO2. Am J Pathol 70:175-198

96. Reddy R, Buckley S, Doerken M, Barsky L, Weinberg K, Anderson KD, Warburton D, Driscoll B 2004 Isolation of a putative progenitor subpopulation of alveolar epithelial type 2 cells. Am J Physiol Lung Cell Mol Physiol 286:L658-L667

97. Cheek JM, Kim KJ, Crandall ED 1989 Tight monolayers of rat alveolar epithelial cells: bioelectric properties and active sodium transport. Am J Physiol 256:C688C693

98. Danto SI, Zabski SM, Crandall ED 1992 Reactivity of alveolar epithelial cells in primary culture with type I cell monoclonal antibodies. Am J Respir Cell Mol Biol 6:296-306

99. Borok Z, Danto SI, Lubman RL, Cao Y, Williams MC, Crandall ED 1998 Modulation of tlalpha expression with alveolar epithelial cell phenotype in vitro. Am J Physiol 275:L155-L164

100. Borok Z, Lubman RL, Danto SI, Zhang XL, Zabski SM, King LS, Lee DM, Agre P, Crandall ED 1998 Keratinocyte growth factor modulates alveolar epithelial cell phenotype in vitro: expression of aquaporin 5. Am J Respir Cell Mol Biol 18:554-561

101. Dobbs LG, Williams MC, Brandt AE 1985 Changes in biochemical characteristics and pattern of lectin binding of alveolar type II cells with time in culture. Biochim Biophys Acta 846:155-166
102. Shannon JM, Jennings SD, Nielsen LD 1992 Modulation of alveolar type II cell differentiated function in vitro. Am J Physiol 262:L427-L436

103. Goodell MA, Brose K, Paradis G, Conner AS, Mulligan RC 1996 Isolation and functional properties of murine hematopoietic stem cells that are replicating in vivo. J Exp Med 183:1797-1806

104. Zhou S, Schuetz JD, Bunting KD, Colapietro AM, Sampath J, Morris JJ, Lagutina I, Grosveld GC, Osawa M, Nakauchi H, Sorrentino BP 2001 The ABC transporter Bcrp1/ABCG2 is expressed in a wide variety of stem cells and is a molecular determinant of the side-population phenotype. Nat Med 7:1028-1034

105. Zhou S, Morris JJ, Barnes Y, Lan L, Schuetz JD, Sorrentino BP 2002 Bcrp1 gene expression is required for normal numbers of side population stem cells in mice, and confers relative protection to mitoxantrone in hematopoietic cells in vivo. Proc Natl Acad Sci U S A 99:12339-12344

106. Kotton DN, Summer R, Fine A 2004 Lung stem cells: new paradigms. Exp Hematol 32:340-343

107. Jackson KA, Majka SM, Wang H, Pocius J, Hartley CJ, Majesky MW, Entman ML, Michael LH, Hirschi KK, Goodell MA 2001 Regeneration of ischemic cardiac muscle and vascular endothelium by adult stem cells. J Clin Invest 107:1395-1402

108. Asakura A, Seale P, Girgis-Gabardo A, Rudnicki MA 2002 Myogenic specification of side population cells in skeletal muscle. J Cell Biol 159:123-134

109. Wulf GG, Luo KL, Jackson KA, Brenner MK, Goodell MA 2003 Cells of the hepatic side population contribute to liver regeneration and can be replenished with bone marrow stem cells. Haematologica 88:368-378

110. Asakura A, Rudnicki MA 2002 Side population cells from diverse adult tissues are capable of in vitro hematopoietic differentiation. Exp Hematol 30:1339-1345

111. Summer R, Kotton DN, Sun X, Ma B, Fitzsimmons K, Fine A 2003 Side population cells and Bcrp1 expression in lung. Am J Physiol Lung Cell Mol Physiol 285:L97L 104

112. Summer R, Kotton DN, Sun X, Fitzsimmons K, Fine A 2004 Translational physiology: origin and phenotype of lung side population cells. Am J Physiol Lung Cell Mol Physiol 287:L477-L483

113. Liang SX, Summer R, Sun X, Fine A 2005 Gene expression profiling and localization of Hoechst-effluxing CD45- and CD45+ cells in the embryonic mouse lung. Physiol Genomics 23:172-181 